\title{
EL CUIDADO DE LA VEJEZ COMO RESPONSABILIDAD COLECTIVA
}

\section{CARING FOR OLD AGE AS COLLECTIVE RESPONSIBILITY

\author{
Dra. en Ciencias sociales Mariana Aguirre Richero / Prof. Adjunta de la Facultad de Ciencias sociales \\ Departamento de Irabajo Social - UdelaR I mariana.aguirre@cienciassociales. edu. uy \\ Articulo Recibido: 1 de junio 2020 - Articulo Aceptado: 27 de julio 2020
}

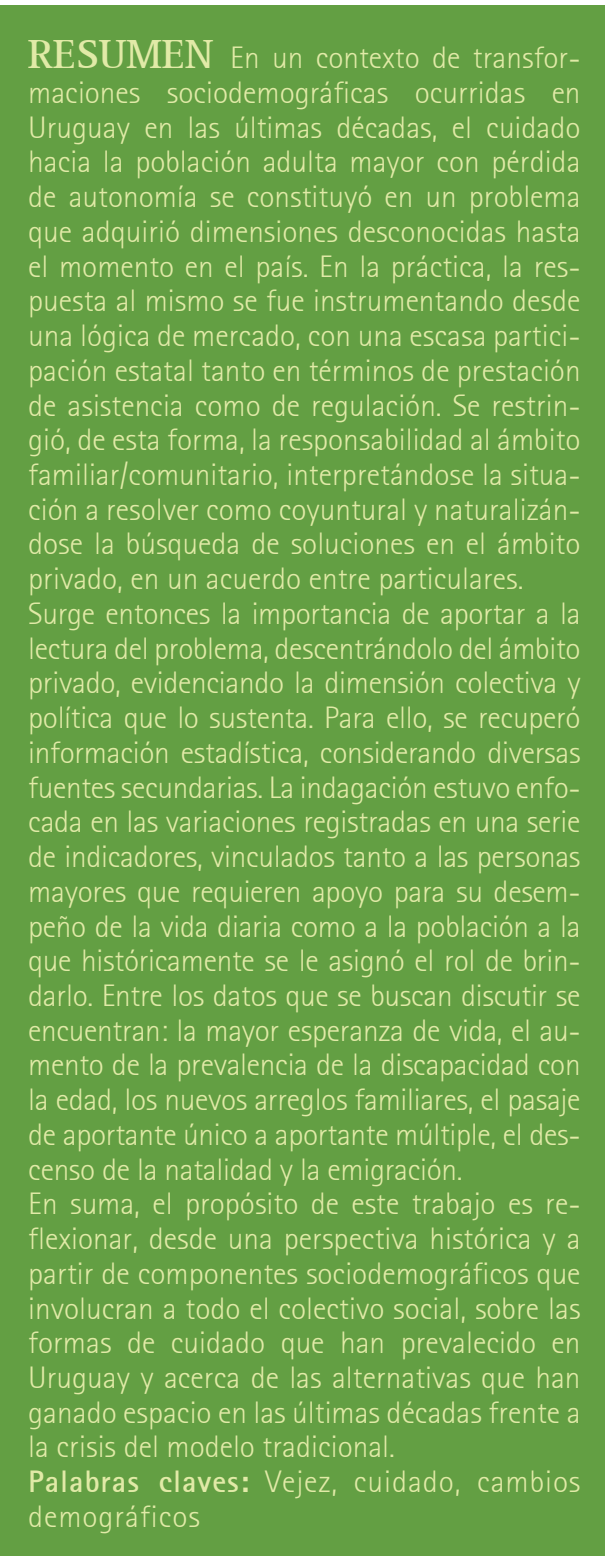

' En particular del censo de 2011 (último censo realizado en Uruguay).

\footnotetext{
${ }^{2}$ De acuerdo a las normativas vigentes, en Uruguay son definidas como "personas adultas mayores" (PAM) o "personas mayores" (PM) aquellas que hayan cumplido los 65 años de edad (Ley 17066 de 1998 y Decreto 365/016, artículo 2 de 2016, respectivamente).
}

\section{INTRODUCCIÓN}

El objetivo de este artículo es aportar a la reflexión sobre la situación del cuidado de la vejez en el Uruguay del siglo XXI. Para ello, se presentan en forma vinculada una serie de datos que permite analizar información estadística de distintos periodos del pais. Los mismos son recuperados a partir de la base de datos del Instituto Nacional de Estadistica (INE) ${ }^{1}$ y de bibliografía producida con relación a la temática.

En las últimas décadas se conjugó una serie de transformaciones sociodemográficas que pusieron en jaque a las prácticas de cuidado que habian prevalecido en Uruguay hasta la primera mitad del siglo XX. Es posible agrupar los cambios registrados en dos grandes dimensiones: por un lado, el aumento de la población adulta mayor $\underline{2}$ a partir de un crecimiento significativo tanto de la esperanza de vida como de la prevalencia de la pérdida de autonomía en el desempeño de las actividades de la vida diaria a medida que aumenta la edad; por el otro, la disminución de la capacidad de cuidado en los ámbitos familiar y comunitario, a partir de los cambios registrados en los arreglos familiares y en la población "cuidadora".

La combinación de estas transformaciones y el impacto de las mismas en los sistemas de cuidado representan un desafío para el presente y el futuro inmediato. Progresivamente, el déficit en el sistema de cuidado ha sido cubierto por el mercado. Es ejemplo de esto que, de acuerdo a datos oficiales en Uruguay, el 90\% de las "residencias de larga estadia" (también denominadas "casas de salud" o "residenciales") se encuentran dentro de la órbita privada, regulada por las leyes del mercado, y solo el 10\% de los establecimientos del pais son estatales o emprendimientos privados sin fines de lucro que cuentan con el apoyo de políticas públicas (Pugliese, 2007: 148-149; Ministerio de DesarroIlo Social (Mides) e Instituto Nacional de las Personas Mayores (Inmayores), Cuadro 2, 2016: 2). Se suma a lo anterior la escasa información pública sobre el tema y la baja regulación estatal. Siguiendo con el ejemplo planteado, y también de acuerdo a datos oficiales, solo el $2 \%$ de los residenciales se encuentran 
De Prácticas y discursos

Universidad Nacional del Nordeste

Centro de Estudios Sociales

Año 9, Número 14, 2020, Octubre

ISSN 2250-6942

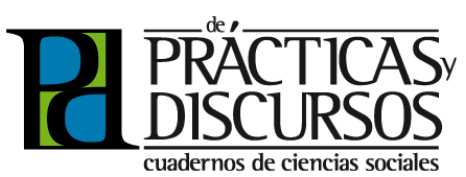

ABSTRACT In a context of sociodemographic transformations that have occurred in Uruguay in recent decades, caring for the elderly population with loss of autonomy has become a problem that has hitherto been unknown in the country. In practice, the response to it was implemented from a market logic with little state participation both in terms of providing assistance and regulation. In this way, responsibility was restricted to the family / community sphere, interpreting the situation to be solved as conjunctural and naturalizing the search for solutions in the private sphere, in an agreement between individuals.

So the importance of contributing to the reading of the problem arises, releasing it from the private sphere, showing the collective and political dimension that supports it. For this, statistical information was retrieved, considering various secondary sources. The investigation focused on the variations registered in a series of indicators, linked both to the Elderly People who require support for their daily life performance, and to the population that historically was assigned the role of providing it. Among the data that are sought to be discussed are: increased life expectancy, the increase in the prevalence of disability with age, new family arrangements, the passage from single contributor to multiple contributor decreased birth rate and emigration.

In short, the purpose of this work is to reflect, from a historical perspective and from sociodemographic components that involve the entire social group, about the forms of care that have prevailed in Uruguay and about the alternatives that have gained space in recent years, decades before the crisis of the traditional model.

Key Words: Old age, care, demographic change

${ }^{3}$ El estudio se realizó durante nueve meses en Uruguay (mayo 2015-febrero 2016) y fue llevado adelante por el Ministerio de Desarrollo Social (Mides) y el Instituto Nacional de las Personas Mayores (Inmayores, 2016).

${ }^{4}$ Dice en su artículo 2 de la Ley 19353: "La presente ley tiene por objeto la promoción del desarrollo de la autonomía de las personas en situación de dependencia, su atención y asistencia, mediante la creación del Sistema Nacional Integrado de Cuidados (SNIC), como conjunto de acciones y medidas orientadas al diseño e implementación de políticas públicas que constituyan un modelo solidario y corresponsable entre familias, Estado, comunidad y mercado".

\footnotetext{
${ }^{5}$ Dentro de su población objetivo se incluyen niñas y niños de hasta doce años, personas con discapacidad y "personas mayores de sesenta y cinco años que carecen de autonomía para desarrollar las actividades y atender por sí mismas sus necesidades básicas de la vida diaria" (artículo 8, Ley 19353).
}

habilitados para trabajar de acuerdo a las normativas vigentes (Ministerio de Salud Pública, 2018).

La naturalización del lucro en las prácticas de cuidado y la muy escasa intervención estatal tanto a nivel de asistencia como de control de los servicios privados deriva necesariamente en diferencias significativas entre las prestaciones ofertadas, quedando las mismas sujetas a la capacidad de pago, a las leyes de oferta y demanda, y a la maximización de la ganancia.

La situación así planteada ha transformado el tema del cuidado en un acuerdo entre privados (cliente-oferente), entendida su dinámica en términos coyunturales y circunstanciales, quitándole al problema su carácter estructural y colectivo, en tanto afecta a toda la sociedad en forma directa o potencial y vulnera garantías de la población.

Estos datos toman una mayor significación si se consideran además las escasas alternativas de cuidado a las residencias de larga estadía en Uruguay. Sobre el total de establecimientos relevados por el estudio realizado por el Ministerio de Desarrollo Social ${ }^{3}$, solo el 3,9\% de los casos eran propuestas de "inserción familiar" (Cuadro 2, Mides, Inmayores, 2016: 2).

Si bien en 2015 se aprobó la Ley 19353 del Sistema Nacional Integrado de Cuidados ${ }^{4}$ (SNIC), los nuevos parámetros establecidos por la normativa sobre los derechos a la asistencia y protección, y fundamentalmente los recursos asignados para su implementación, resultan claramente insuficientes para revertir la "crisis de los cuidados", entendida como "la puesta en evidencia y agudización de las dificultades de amplios sectores de la población para cuidarse, cuidar o ser cuidados" (Ezquerra, 2011: 176).

Aun así, cabe señalar un primer movimiento que esta normativa supuso hacia el reconocimiento de la responsabilidad estatal y la diversificación de las alternativas de cuidados: hogares diurnos (nueve en todo el país) dirigidos a personas mayores de 65 años con niveles de dependencia leve y moderada, asistentes personales para situaciones de dependencia severa y un servicio de teleasistencia en el hogar para mayores de 70 años.

\section{AUMENTO DE LA POBLACIÓN ADULTA MAYOR}

Los cambios en la pirámide poblacional es el primer aspecto a mencionar con relación al incremento de la población adulta mayor. Los avances tecnológicos en el campo de la medicina han permitido aumentar la esperanza de vida y extenderla hasta lí- 


\begin{abstract}
${ }^{5} \mathrm{El}$ contenido de las entrevistas fue procesado a partir de la aplicación de la técnica para el análisis de discursos que propone Enrique Martín Criado (2010, 2014). Esta técnica, se entiende, guarda concordancia con referencias teóricas como las de Bourdieu, definidas en el marco conceptual. Interesaba que los discursos fueran analizados a la luz de una técnica que pusiera foco en aspectos simbólicos que permitan descifrar el "decir del hacer”, la justificación o argumentación de las prácticas, así como dar cuenta de representaciones que signan los modos de pensar, sentir y hacer de quienes fueron parte de la unidad de análisis de esta investigación.
\end{abstract}

${ }^{6}$ Entre 2005 y 2009 se da un aumento presupuestal de la Administración Nacional de Educación Pública (Anep) de un 71\%.

${ }^{7}$ La "era progresista” (Garcé y Jaffé, 2004) hace referencia a las tres administraciones de gobierno frenteamplistas. El Frente Amplio ascendió al Ejecutivo por primera vez el $1^{\circ}$ de marzo de 2005 , permaneciendo durante 15 años. mites inéditos en la historia de la humanidad. Por esperanza de vida se entiende "una estimación del número promedio de años de vida adicionales que una persona podría esperar vivir si las tasas de mortalidad por edad específica para un año determinado permanecieran durante el resto de su vida" (Haupt y Kane, 2003: 28). En Uruguay, este indicador pasó de 66 años en 1955 a 77,55 años en 2017 (Instituto Nacional de Estadística-INE).

Una serie de datos aporta sobre el tema. Al comienzo de la segunda mitad del siglo XX, el porcentaje de muertes anuales de las personas mayores de 64 años (sobre el total de la población) alcanzaba un 35\% en los varones y un $42 \%$ en las mujeres. Medio siglo después (2006), estos porcentajes se habían duplicado: por cada mil muertes, un 69,6\% correspondía a varones mayores de 64 años y un 82,1\%, a mujeres en igual rango de edad (Cabella y Pellegrino, 2010). También en este período varió el peso relativo de las distintas causas de defunción. Las "enfermedades infecciosas y parasitarias" descendieron un 19\% sobre el total de las muertes (del 21\% en la década de 1940 al 2\% en 2000), mientras que las enfermedades cardiovasculares y el cáncer pasaron a representar el 60\% de las causas de muerte a principios del siglo XXI (Pellegrino, Cabella, Paredes, Pollero y Varela, 2008). En Uruguay, la primera transición demográfica se dio en forma temprana. Se denomina transición demográfica al proceso a través del cual una población disminuye las tasas de mortalidad y natalidad. En los momentos en que ambas tasas son altas o bajas, se registra un estado de equilibrio del que resulta un bajo (o nulo) crecimiento de la población. El motor desencadenante de esta transición se atribuye al descenso de la mortalidad, seguido por un descenso de la natalidad. El período de desfasaje entre estos descensos da lugar a la "explosión demográfica" caracterizada por un crecimiento poblacional (Pellegrino et al., 2008). Vinculada a la transición demográfica y al debate de las causas del descenso de la mortalidad se encuentra la Teoría de la transición sanitaria. Ambos fenómenos poblacionales, si bien difieren en su esencia, están fuertemente vinculados (Possas, 1993). Se entiende la transición sanitaria como "un proceso dinámico, donde los patrones de salud y enfermedad aparecen como respuesta a los cambios demográficos, socioeconómicos, tecnológicos, políticos, culturales y biológicos que tienen lugar" (Frenk et al., 1991b: 487, citado en Robles, Bernabeu y Benavidez, 1996: 132).

Uno de los principales aportes de esta teoría es el estudio del 
De Prácticas y discursos

Universidad Nacional del Nordeste

Centro de Estudios Sociales

Año 9, Número 14, 2020, Octubre

ISSN 2250-6942

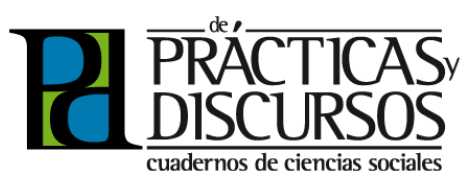

estado de salud de la población a partir de determinantes sociales, culturales y del comportamiento a escala comunitaria, familiar y/o individual. Para ello, relaciona elementos de las teorías clásicas de mejoramiento de la salud pública y de los recursos socioeconómicos como causas del descenso de la mortalidad. Sus fundamentaciones vinculan los aportes realizados desde tres perspectivas: la transición epidemiológica, la transición de la atención sanitaria y la transición de riesgos.

La transición epidemiológica representa el tránsito de una etapa con enfermedades infecciosas como la principal causa de altos niveles de mortalidad a otra con disminución de la mortalidad y enfermedades degenerativas como principal causa de muerte (Robles, et al., 1996). El otro aporte explicativo es tomado de la transición de la atención sanitaria, la cual estudia los cambios "de la organización de la respuesta colectiva y/o individual a los episodios de enfermedad y los problemas de salud. En otras palabras, la transformación en la forma en que el sistema de salud se organiza para el suministro de servicios" (Robles, et al., 1996: 192). Finalmente, la transición de riesgos considera el análisis de la influencia de la exposición a riesgos de salud ambiental y/o laboral, y la sustitución de los "riesgos tradicionales" en "riesgos modernos". Atendiendo a estas perspectivas y tomando los aportes de diversos autores uruguayos (Adela Pellegrino, Wanda Cabella, Mariana Paredes, Raquel Pollero, Carmen Varela y Juan José Calvo), la primera transición demográfica en Uruguay estuvo apoyada en una multiplicidad de factores sociales, políticos, económicos y culturales. Contó con una fuerte intervención estatal que incidió en forma gravitante en las transformaciones registradas. Al comienzo, a través de la implementación de políticas educativas y sanitarias que repercutieron en las respuestas a las enfermedades, su tratamiento y prevención. Décadas más tarde, la intervención estatal se instrumentó en políticas focalizadas en sectores de población que aún mantenian patrones demográficos pretransicionales (altas tasas de mortalidad y de pautas reproductivas). Como resultado de estas transformaciones, en Uruguay a lo largo del último siglo, aumentó 30 años la esperanza de vida al nacer.

Dos conceptos complementan la información anterior: la "estructura de edad" y el "indice de envejecimiento". La denominada "estructura de edad" representa la forma en que se distribuyen los grupos de edades en una población dada, considerándose una "estructura de edad envejecida" cuando el 7\% 
${ }^{6}$ INE. Cuadro: Uruguay; indicadores de estructura por sexo y edad de la población. Período 1996-2050.

${ }^{7}$ INE. Cuadro: Uruguay: indicadores de estructura por sexo y edad de la población. Período 1996-2050. del total de la población es mayor de 60 años. Esta condición ya estaba presente en el país en la mitad del siglo XX y ha aumentado en forma sensible hasta el momento actual. Los datos censales indican que en 1963 habia un 7,6\% de personas de 65 y más años (11,6\% de 60 y más años) y en el censo 2011 el porcentaje había subido a 14,1\% (INE, 2011). Este último porcentaje representa en números netos que 463726 personas tienen más de 64 años, ubicando al Uruguay dentro de los paises de América Latina con el mayor peso relativo de dicho grupo de población (Paredes, Ciarniello y Brunet, 2010).

Por su parte, el "índice de envejecimiento" es entendido como el "total de población de 65 años y más, dividido la población de 0 a 14 años" (Brunet y Márquez, 2016: 11). En Uruguay, la cifra asciende a 69,646, lo cual expresa que cada 70 personas adultas mayores, hay 100 personas menores de 15 años.

Otro aporte con relación a la estructura de edades lo brinda la distribución de los rangos etarios a partir de los 65 años. A partir de la segunda mitad del siglo $X X$, no solo aumentó la esperanza de vida de la población en general, sino que también creció la expectativa de vida de la población envejecida: "entre las mujeres la esperanza de vida a los 60 años pasó de 19 a 24 años entre 1950 y 2005, mientras que los hombres ganaron cuatro años en su expectativa a partir de los 60 años (de 15 a 19 años)" (Cabella y Pellegrino, 2010: 8).

Este cambio en el perfil de la población adulta mayor es denominado "sobreenvejecimiento" y se define como el "peso relativo de la población que tiene 85 y más años en la población de 65 y más años" (INE). Dicho índice alcanza el $13,65^{7}$ en Uruguay (INE, 2017). Con respecto a este fenómeno, se habla a partir de los 80 años de la "cuarta edad" y del "envejecimiento de la vejez" (Vera, 1996). Da cuenta de esta situación la distribución de las franjas etarias de los adultos mayores. De acuerdo al censo de 2011, en Uruguay se encuentran los siguientes porcentajes por tramos etarios: 52,61\% (entre 65 y 74 años), 20,20\% (entre 75 y 79 años) y 27,19\% (con más de 80 años), representando este último tramo el 3,83\% de la población total del país (Thevenet, 2013).

Con respecto al perfil de la población que requiere cuidados, surge un segundo fenómeno vinculado al envejecimiento y el sobreenvejecimiento. Es la denominada "feminización de la vejez", resultado de la mayor esperanza de vida de las mujeres (80,46 años) que de los varones (73,62 años). Refuerza esta tendencia la "esperanza proyectada para las personas de 65 años y más" (Brunet y Márquez, 2016: 6). 
De Prácticas y discursos

Universidad Nacional del Nordeste

Centro de Estudios Sociales

Año 9, Número 14, 2020, Octubre

ISSN 2250-6942
${ }^{8}$ Para este estudio solo se considera a quienes viven en hogares particulares (Brunet y Márquez, 2016). a medida que pasa el tiempo y se sobrevive a cada año, los años por vivir aumentan. Es por eso que al llegar a los 60 años la esperanza de vida es de 18 años para los varones $y$ de 24 años para las mujeres. Es decir, las mujeres vivirán hasta los 84 años y los varones hasta los 78 años. Sin embargo, superados los 70 años, los varones vivirán, en promedio, hasta los 81 y las mujeres hasta los 86, acortándose la brecha en las edades más avanzadas (Paredes et al., 2010: 16).

Como resultado de este proceso, sobre el total de personas mayores de 64 años $^{8}(457662)$, el 88\% se encuentra dentro del rango de edad entre 65 y 84 años, con un incremento del porcentaje femenino a medida que avanza la edad. "En términos relativos, de cada 10 personas mayores de 64 años, 6 son mujeres; y dentro del grupo de mayores de 84, menos de 3 de cada 10 son varones" (Brunet y Márquez, 2016: 73).

El Gráfico 1 representa la distribución de la población mayor de 64 años según rangos de edad y sexo, evidenciando el mayor peso relativo de las mujeres en prácticamente todos los tramos etarios. La relación de masculinidad en el total de la población uruguaya es de 92,32 hombres cada 100 mujeres. A partir de los 65 años, esta relación desciende a 65,88 hombres cada 100 mujeres y desde los 79 años la relación pasa a ser de 47,98 (Thevenet, 2013).

Otro dato relevante en este sentido lo aporta la mediana de la edad de la población. En nuestro país es de 32 años, siendo la mayor de todos los paises de América Latina (Paredes et al., 2010).

\section{DEPENDENCIA EN LA VEJEZ}

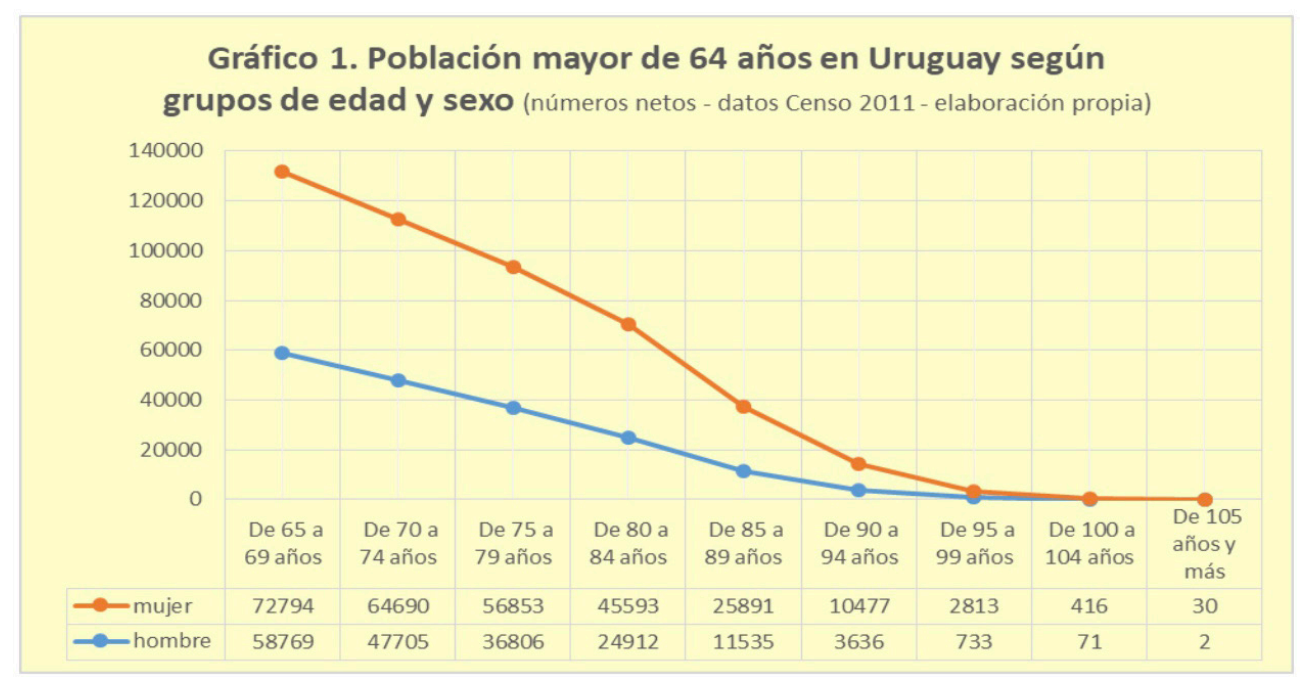




\begin{abstract}
${ }^{9}$ Prevalencia de limitaciones implica la presencia de alguna limitación en las personas, sin diferenciar el nivel de las mismas. Indica simplemente si presenta o no presenta limitaciones (Thevenet, 2013, p. 18).

${ }^{10}$ El Censo 2011 formuló una serie de preguntas dirigidas a identificar «dificultades permanentes que las personas pueden tener para realizar ciertas actividades habituales debido a un problema de salud" (Brunet y Márquez, 2016, p. 21).

11 Cuadro 2. Población por alguna discapacidad permanente (para ver, oír, caminar o aprender o entender) según sexo y edad. Total del país (INE).

\footnotetext{
${ }^{12}$ Equivalente a 65.363 personas.

${ }^{13}$ Equivalente a 65.363 personas.

${ }^{14}$ Se preguntaba si la persona tenía dificultades para ver (aún si usa anteojos), oír (aún si usa audífonos), caminar o subir escalones (mayores de 2 años) y entender o aprender (6 años o más). Las respuestas se organizaban en las siguientes categorías: No tiene dificultad, alguna dificultad, mucha dificultad, no puede hacerlo. Instituto Nacional de Estadística (1996) Manual Del Empadronador. Vll Censo General de Población, 111 de Hogares y $V$ de Viviendas. Uruguay: Centro Latinoamericano $Y$ Caribeño De Demografía (Celade).
}

${ }^{15}$ Equivalente a 74.985 personas.

${ }^{16}$ Equivalente a 49875 personas.
La prevalencia ${ }^{9}$ de la pérdida de autovalidez en la población de 65 años y más resulta también una información importante a considerar. Los datos arrojados por el censo de $2011^{10}$ sobre discapacidad ${ }^{11}$ evidencian un incremento a medida que aumenta la edad: de un total de 240703 personas con edades comprendidas entre 65 años y 74 años, el $27 \% \%^{12}$ presenta una discapacidad leve y el $11 \% 0^{13}$, una discapacidad moderada o severa, lo cual supone que requieren apoyo para actividades diarias (INE, 2011) ${ }^{14}$. Estos porcentajes aumentan considerablemente en la franja etaria de 75 años y más. Sobre un total de 216968 personas que pertenecen a este último grupo etario, un 34,5\% ${ }^{15}$ presenta discapacidad leve y un $23 \% \%^{16}$, moderada o severa. Con respecto al tipo de discapacidad relevada, aporta Thevenet (2013: 19):

El 94,37\% de las personas Adultas Mayores no tienen difcultades para entender y/o aprender y el 83,34\% no tiene dificultades para oír. En los casos de caminar y ver, es donde se observan mayores dificultades. La mayor incidencia de la discapacidad en las personas adultas mayores se registra en las dificultades para caminar y ver, en donde solamente el $71,44 \%$ y el 72,14\% de estas personas no tienen dificultades.

Si se considera ahora el grado de pérdida de autonomía, hay dos condiciones que importan por su incidencia en el requerimiento de apoyo para la vida diaria. Estas dos categorias abarcan las respuestas: "sí, no puedo hacerlo" y "sí, mucha dificultad".

El Gráfico 2 muestra cómo la suma de dichas respuestas aparece con mayor peso en las áreas de "caminar" y "ver" (10,23\% "caminar" y 6,76\% "ver"). Aun así, la población con estos niveles de discapacidad representan una minoría de la población adulta mayor.

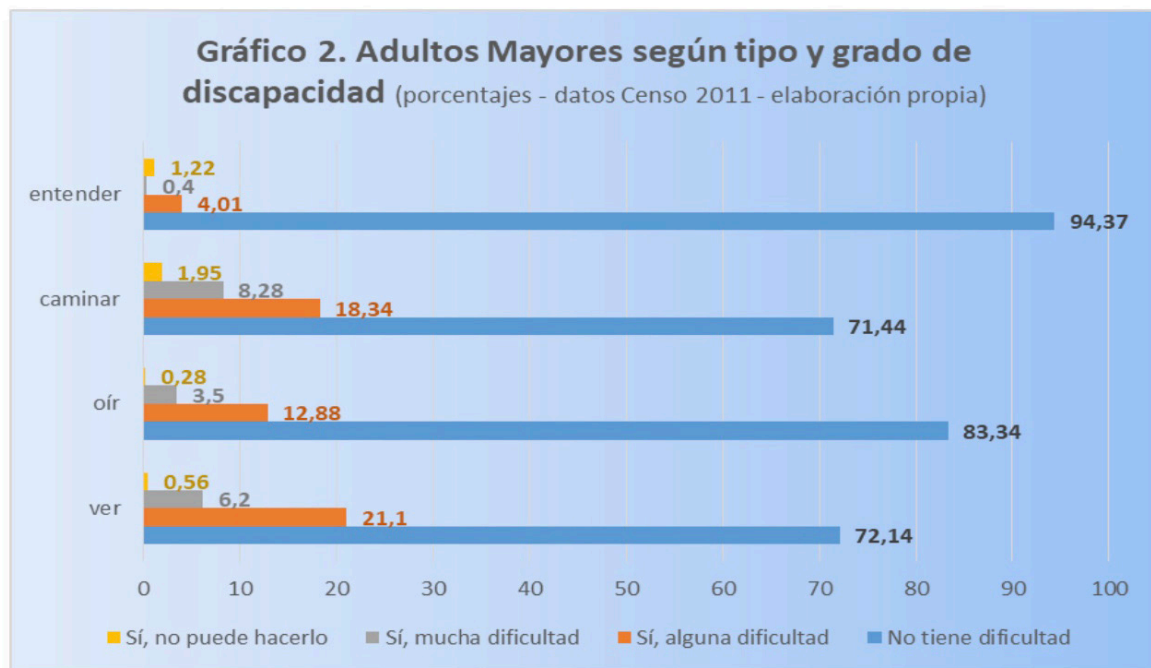


De Prácticas y discursos

Universidad Nacional del Nordeste

Centro de Estudios Sociales

Año 9, Número 14, 2020, Octubre

ISSN 2250-6942

\begin{abstract}
${ }^{17}$ Importa tener en cuenta que estos datos no incluyen a personas que viven en la categoria "residencial de ancianos”. La información manejada hasta el momento es aportada por el Censo 2011, donde hay un claro subregistro del dato referido a las personas residentes en instituciones de cuidado. Solo fueron relevadas menos del 5\% del total de personas residentes en las instituciones de todo el país (el porcentaje restante se encuentra en las categorías: "no relevado", "ignorado").
\end{abstract}

${ }_{18}$ Esta dependencia resulta del "cociente entre personas de 65 años y más, entre aquellas de 15 y 64 años (multiplicado por 100)" (Brunet y Márquez, 2016: 14).

${ }^{19}$ Cantidad de personas de 65 años y más: 404843 (Censo 2011).

${ }^{20}$ Cantidad de personas entre 15 y 64 años: 1965049 (Censo 2011).
Por otra parte, si las mismas variables se diferencian por sexo, se evidencia una mayor tendencia a la discapacidad en las mujeres que en los varones.

El Gráfico 3 representa estas diferencias. La franja comprendida entre los 65 a 74 años registra para la "discapacidad leve" una diferencia de 3,38 puntos porcentuales entre ambos sexos (28,6\% mujeres y $25,22 \%$ varones). La misma comparación en las categorías de discapacidad "moderada" o "severa" muestra una diferencia de 3,5 puntos porcentuales entre mujeres y hombres (12,3\% a 8,8\%).
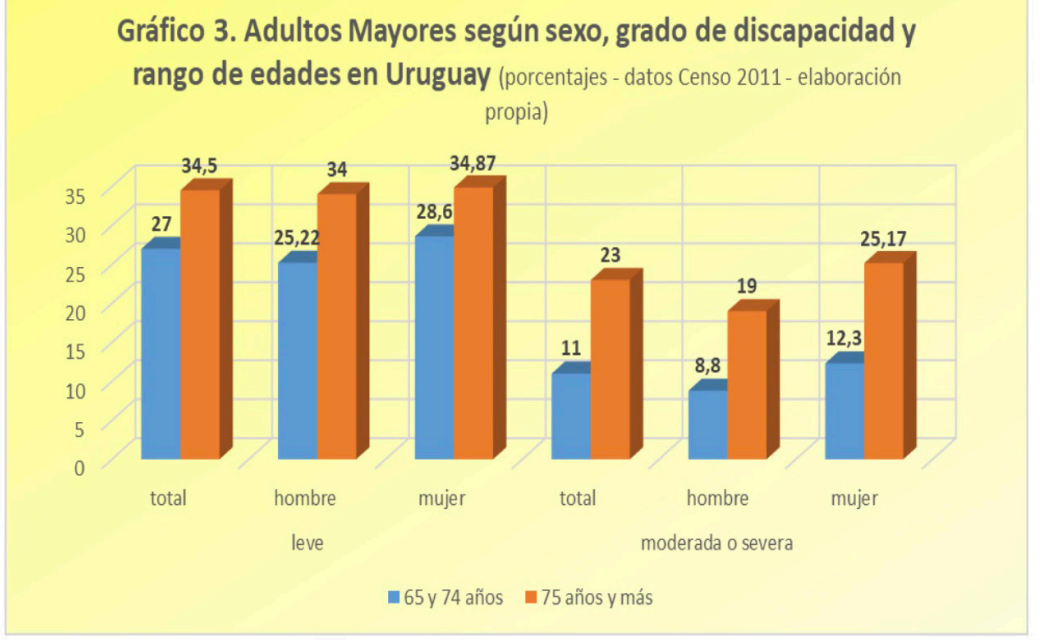

En la franja de 75 años y más, la tendencia de mayor discapacidad en la mujer se mantiene en todos los grados, aunque disminuye la diferencia en la categoría "leve" (34,87\% a 34\%) y aumenta a 6,17\% en las "moderada" y "severa" (25,17\% en mujeres y $19 \%$ en varones) ${ }^{17}$. Acerca de la vejez en Uruguay y su eventual dependencia, hay dos aspectos más que importan mencionar. El primero es la relación con la Población en Edad de Trabajar (PET) ${ }^{18}$ : cada 22 personas de 65 años ${ }^{19}$ y más, existen 100 personas entre 15 y 64 años ${ }^{20}$ (Thevenet, 2013). Esta cifra representa la más alta de la región (incluso superior a Cuba). El segundo aspecto es el denominado "bono demográfico". El concepto hace referencia a las oportunidades de desarrollo sustentadas en la transformación de la estructura de edades que alcanza un equilibrio. "Ocurre cuando cambia favorablemente la relación de dependencia entre la población en edad productiva (jóvenes y adultos) y aquella en edad dependiente (niños y personas mayores), con un mayor peso relativo de la primera en relación a la segunda" (Saad, Miller, Holz y Martínez, 2012: 17). Los datos presentados sobre el caso uruguayo dan cuenta del fin del bono demográfico, ya 
${ }^{21}$ Información presentada en Tabla 2, en Cabella, W. Fernández, M. y Prieto, V. (2015). Fascículo 6. Las transformaciones de los hogares uruguayos vistas a través de los censos de 1999 y 2011. En Calvo, J.J. (coord.) Atlas Socioeconómico y de la desigualdad en Uruguay (pp. 10 y 17). Montevideo: Trilce. ISBN: 9789974-32-645-3. que la disminución de las relaciones de dependencia de la población más joven (0 y 14 años) ha sido sustituida por el aumento de la dependencia de la población envejecida (Paredes, 2008).

\section{AFECTACIÓN DE LAS ESTRATEGIAS DE CUIDADO}

A los cambios mencionados hasta el momento se le suma una serie de transformaciones sociodemográficas que en el último medio siglo afectaron las estrategias de cuidado existentes hasta entonces en el país. Estas pueden ordenarse en dos grandes ejes: los cambios en el tipo de arreglos familiares y la disminución de la población que hasta entonces se hacía cargo del cuidado en los ámbitos familiar y comunitario.

\section{CAMBIOS EN EL TIPO DE ARREGLOS FAMILIARES}

Los cambios ocurridos en los modelos familiares en las últimas décadas revisten importancia, ya que las nuevas estructuras presentan mayores dificultades para afrontar la potencial pérdida de capacidades de sus miembros. En el Gráfico $4^{21}$ se representan estas variaciones intercensales. La tendencia es que los hogares se conformen

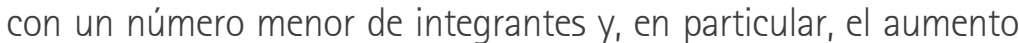
de los hogares unipersonales configura un escenario que impacta en las estrategias cotidianas de cuidados familiares.

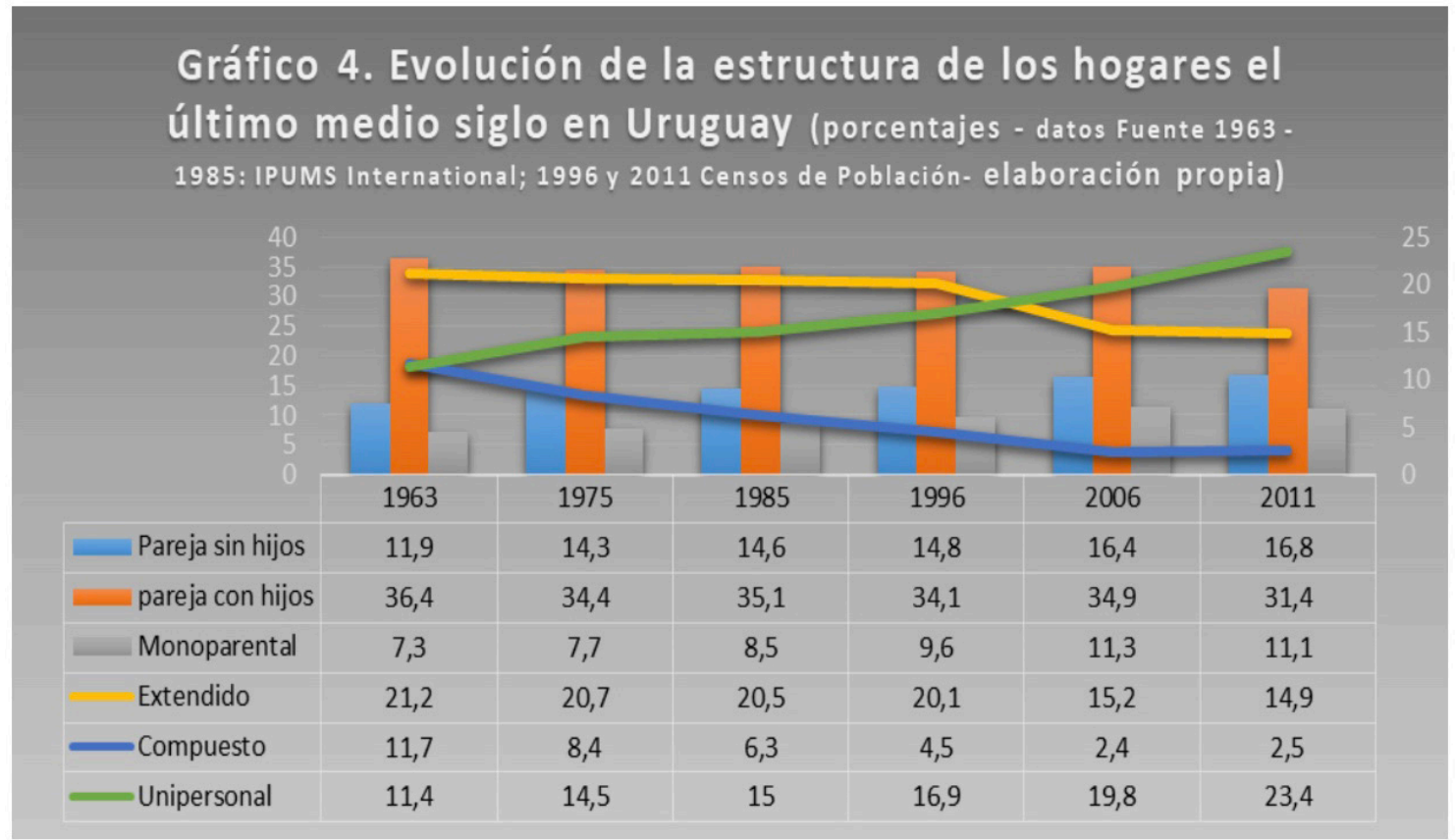


De Prácticas y discursos

Universidad Nacional del Nordeste

Centro de Estudios Sociales

Año 9, Número 14, 2020, 0ctubre

ISSN 2250-6942

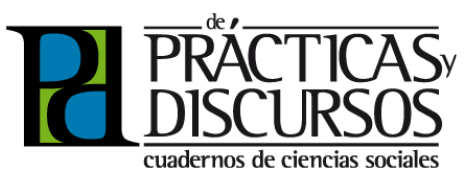

21 La tipología de hogares del INE: Unipersonal: persona viviendo sola; Biparental sin hijos: personas sin hijos en el hogar; Biparental con hijos de ambos: pareja con hijos de ambos cónyuges; Biparental con hijos de al menos un cónyuge: son hogares con pareja e hijos de ambos y/o al menos un miembro de la pareja; Monoparentales femeninos/ masculinos: madres/padres con hijos; Extendidos: pareja o madre/padre con hijos/as y otro pariente; Compuestos: pareja o madre/padre con hijos/as y/u otro pariente $y / u$ otro miembro no pariente.

${ }^{23}$ Información presentada en Tabla 11, Cabella, W.; Fernández, M. y Prieto, V. (2015). Fascículo 6. Las transformaciones de los hogares uruguayos vistas a través de los censos de 1999 y 2011. En Calvo, J.J. (coord.) Atlas Socioeconómico y de la desigualdad en Uruguay (p. 46). Montevideo: Trilce. 1SBN: 978-9974-32-645-3.

24 Información presentada en Tabla 11, en Cabella, W.; Fernández, M. y Prieto, V. (2015). Fascículo 6. Las transformaciones de los hogares uruguayos vistas a través de los censos de 1999 y 2011. En Calvo, J.J. (coord.) Atlas Socioeconómico y de la desigualdad en Uruguay (p. 46). Montevideo: Trilce. 1SBN: 978-9974-32-645-3.
Dentro de los cambios registrados en los arreglos familiares ${ }^{22}$ en el período comprendido entre los censos de 1963 y 2011, se destaca para este estudio el aumento de hogares unipersonales (de 11,4\% a 23,4\%), de parejas sin hijos (de 11,9\% a 16,8\%) y la disminución de hogares compuestos (de 11,7\% a $2,5 \%$ ) y extendidos (21,2\% a $14,9 \%)$.

Si retomamos estas mismas variaciones, pero enfocadas en la participación de los adultos mayores en los hogares, las cifras adquieren una nueva dimensión. En el Gráfico $5^{23}$ se muestra el aumento y disminución de algunos tipos de hogares en los que participan adultos mayores en el período intercensal 1996-2011.

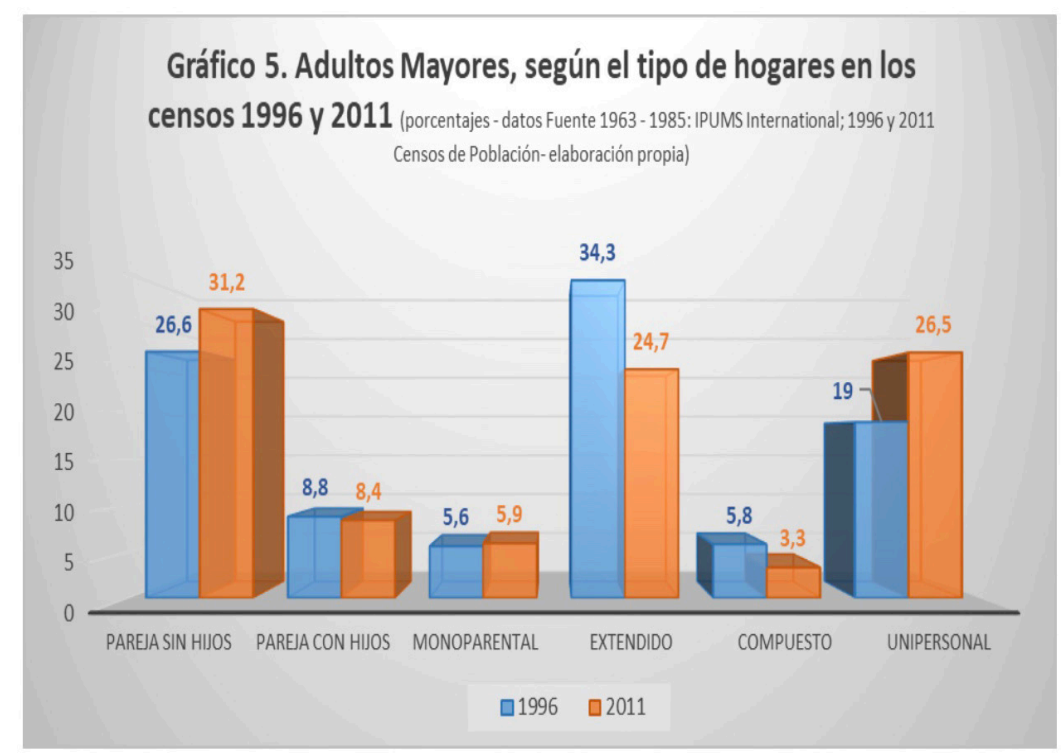

Los hogares unipersonales y de pareja sin hijos aumentaron más (7,5\% unipersonales y 4,6\% parejas sin hijos) que el promedio nacional (6,5\% unipersonales y $2 \%$ parejas sin hijos).

Con respecto a la disminución de los hogares extendidos y de los hogares compuestos, la variación intercensal de las situaciones que involucran a adultos mayores (9,6\% extendido y 2,5\% compuesto), también superó las cifras a escala nacional $(5,1 \%$ extendido y $2 \%$ compuesto). Esta diferencia crece o disminuye para los distintos tipos de hogares a medida que aumenta la edad de las personas.

El Gráfico $6^{24}$ muestra las variaciones entre ambos censos (1996 y 2011) en cuatro tipos de hogares (unipersonales, pareja sin hijos, extendidos y compuestos) según tres grupos de edades. Como se observa en ambos períodos, la participación de los adultos mayores en los hogares extendidos y compuestos aumenta a medida que se tiene más edad y disminuye la 
participación en los hogares conformados por parejas sin hijos. En los hogares unipersonales, si bien en ambos censos la participación de los adultos mayores aumenta con la edad, en el censo de 1996 presenta un leve retroceso en los mayores de 79 años.

Finalmente, si se analiza la composición de los hogares de acuerdo al sexo del adulto mayor, los resultados vuelven a mostrar diferencias. El 30,42\% de las mujeres vive en hogares unipersonales, mientras que los varones lo hacen en un $18,22 \%$.

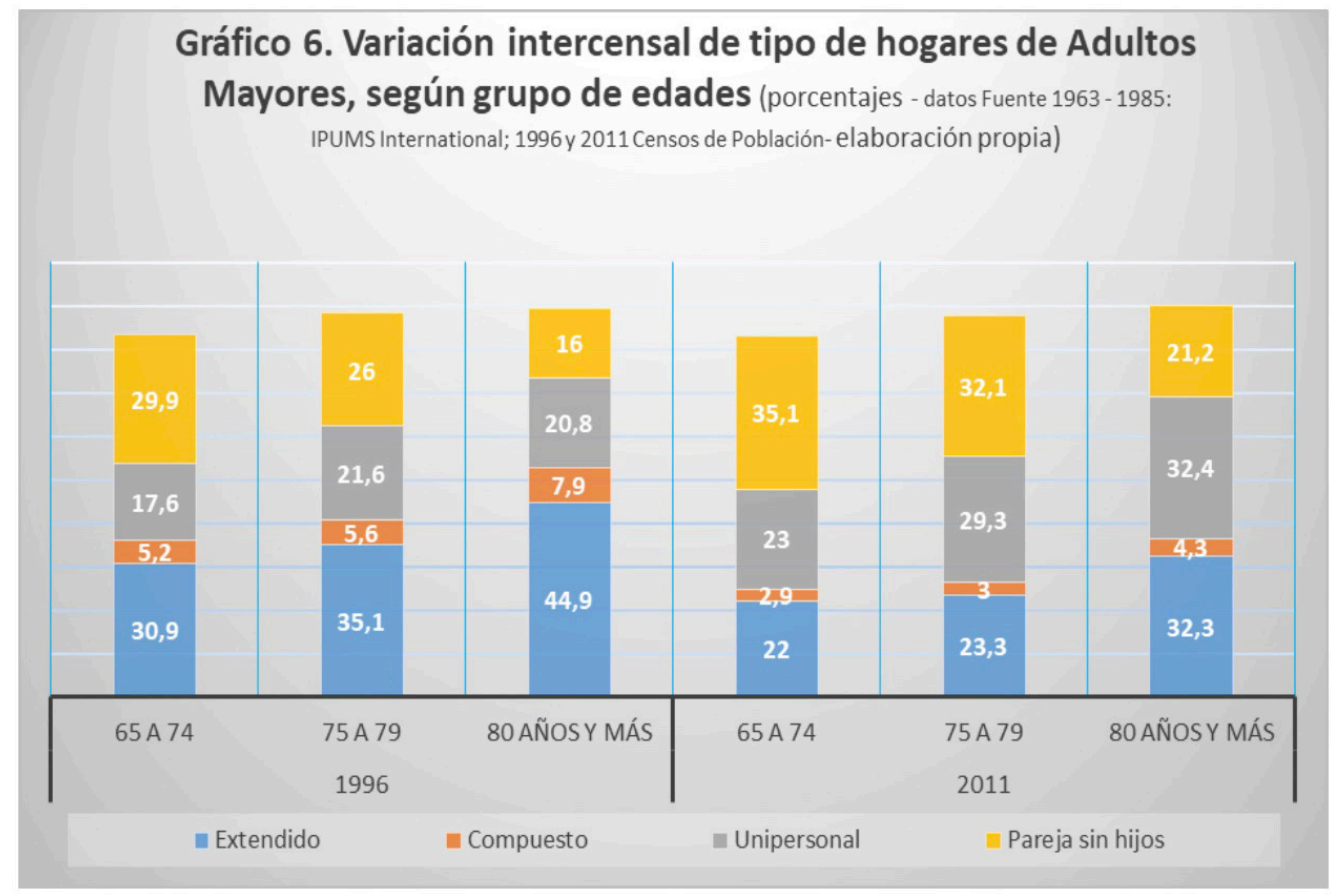

Otro dato significativo lo aporta el hogar nuclear sin hijos: el $21,9 \%$ de las mujeres y el $41,63 \%$ de los varones vive en este tipo de hogares. Se grafica lo expresado a continuación (Gráfico 7).

Más allá de las diferencias, si se consideran los dos tipos de hogares como conformados básicamente por adultos mayores (solos o en pareja), los resultados nos indican que mayoritariamente viven en arreglos familiares sin otras generaciones que operen como potenciales cuidadores. La suma de estos dos arreglos familiares en los varones asciende a 59,85\% y en el caso de las mujeres a 52,32\%, es decir, en promedio el $55,32 \%$ de las personas mayores de 64 años vive en hogares unipersonales o nucleares de pareja sin hijos. 


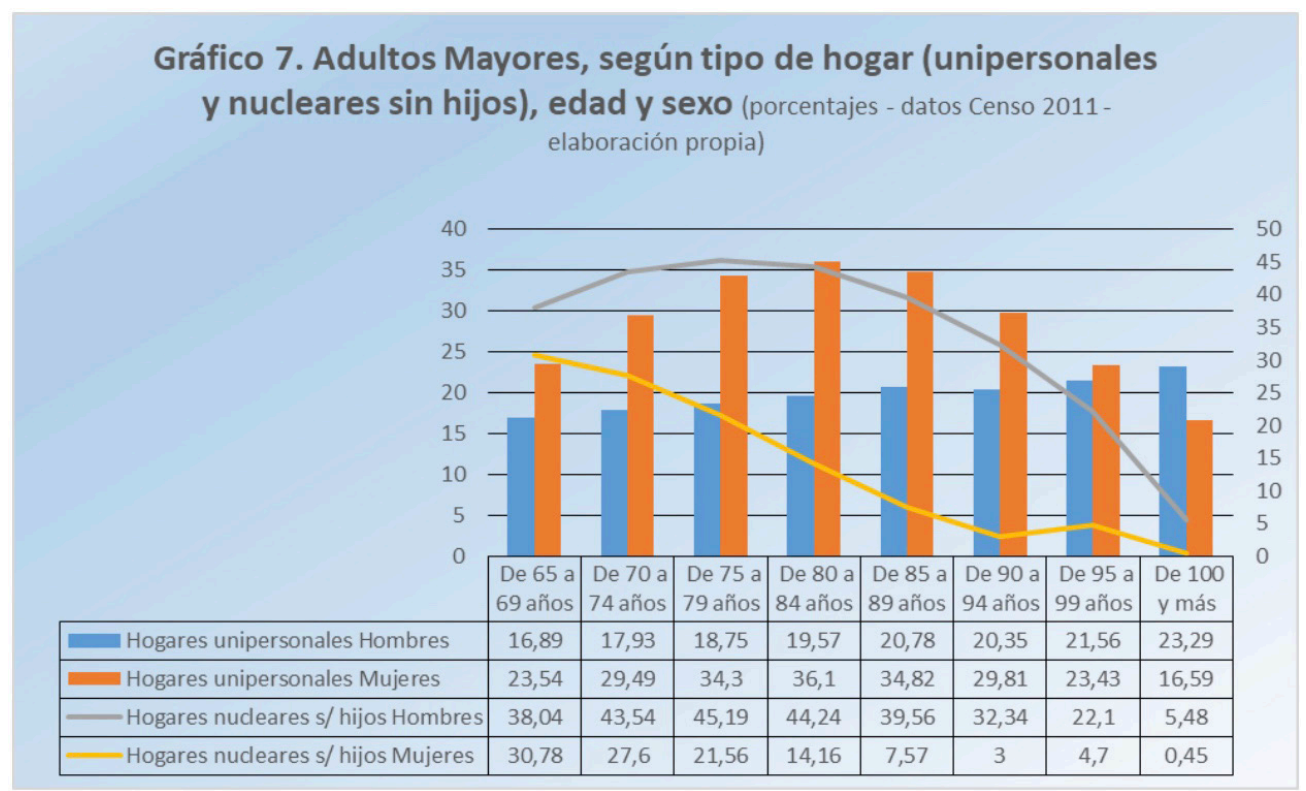

El aumento progresivo de estos dos tipos de hogares y la disminución de los hogares extendidos y compuestos se constata en las mediciones de los últimos 50 años (ver gráficos 4 y 5), por lo que podria preverse que la tendencia continúe en el futuro próximo. La reducción del entorno familiar, y con ello de la red capaz de cuidar en situación de enfermedad o dependencia, se expresa en la denominada "relación de dependencia", la que varía de 100/55 en 1995 a 100/93 en 2025. Se estima que de 5 personas cuidadores promedio en 1950, se pasará a 2 o 3 en 2025, uno de los cuales también será mayor de 65 años" (MSP: 2005/2010). La suma de factores dada por el envejecimiento y sobreenvejecimiento de la población, la feminización de la vejez y los cambios en la relación de dependencia lleva por su parte a que cada vez más las personas adultas mayores ocupen el rol de cuidadoras.

\section{DISMINUCIÓN DE LA POBLACIÓN "CUIDADORA"}

De los diversos factores que afectaron en las últimas décadas el cuidado humano dentro de los ámbitos familiares y comunitarios, este trabajo busca destacar dos por su incidencia en el cuidado de la vejez: el ingreso de la mujer al mercado laboral y la reducción del número de hijos.

Con relación al ingreso de las mujeres en el mercado laboral, las configuraciones familiares presentaron una tendencia que pasó de "aportante único", representado en general por la figura 
masculina, a "aportantes múltiples". Esta actividad remunerada no eximió a la mujer del trabajo doméstico familiar, entendido como las "actividades que producen bienes y servicios para uso de los miembros del hogar sin recibir remuneración" (Aguirre y Scuro, 2008: 20). La nueva dinámica mantuvo un peso relativo superior del trabajo doméstico en las mujeres que en los varones imponiendo una "doble jornada" en la actividad femenina. Este dato se confirma en todos los tramos etarios, aunque "la mayor dedicación de tiempo le corresponde a las mujeres entre 30 y 59 años, quienes a su vez destinan casi el triple que los varones" (Aguirre y Scuro, 2008: 20).

Los estudios sobre la participación femenina en el mercado laboral investigan dos indicadores: la tasa de empleo u ocupación y la tasa de actividad. La tasa de ocupación es entendida como "la proporción de personas que declaran trabajar en forma remunerada con relación al total de la población en edad de trabajar (PET)" (Batthyány et al., 2014: 52). La misma registra un crecimiento importante en la ocupación femenina en las últimas décadas.

\section{Gráfico 8. Tasa de empleo femenino, perído 1986 - 2016}

(datos INE - Localidades de más de 5.000 habitantes - elaboración propia)

$$
60,0
$$

$$
50,0
$$

40,0

30,0
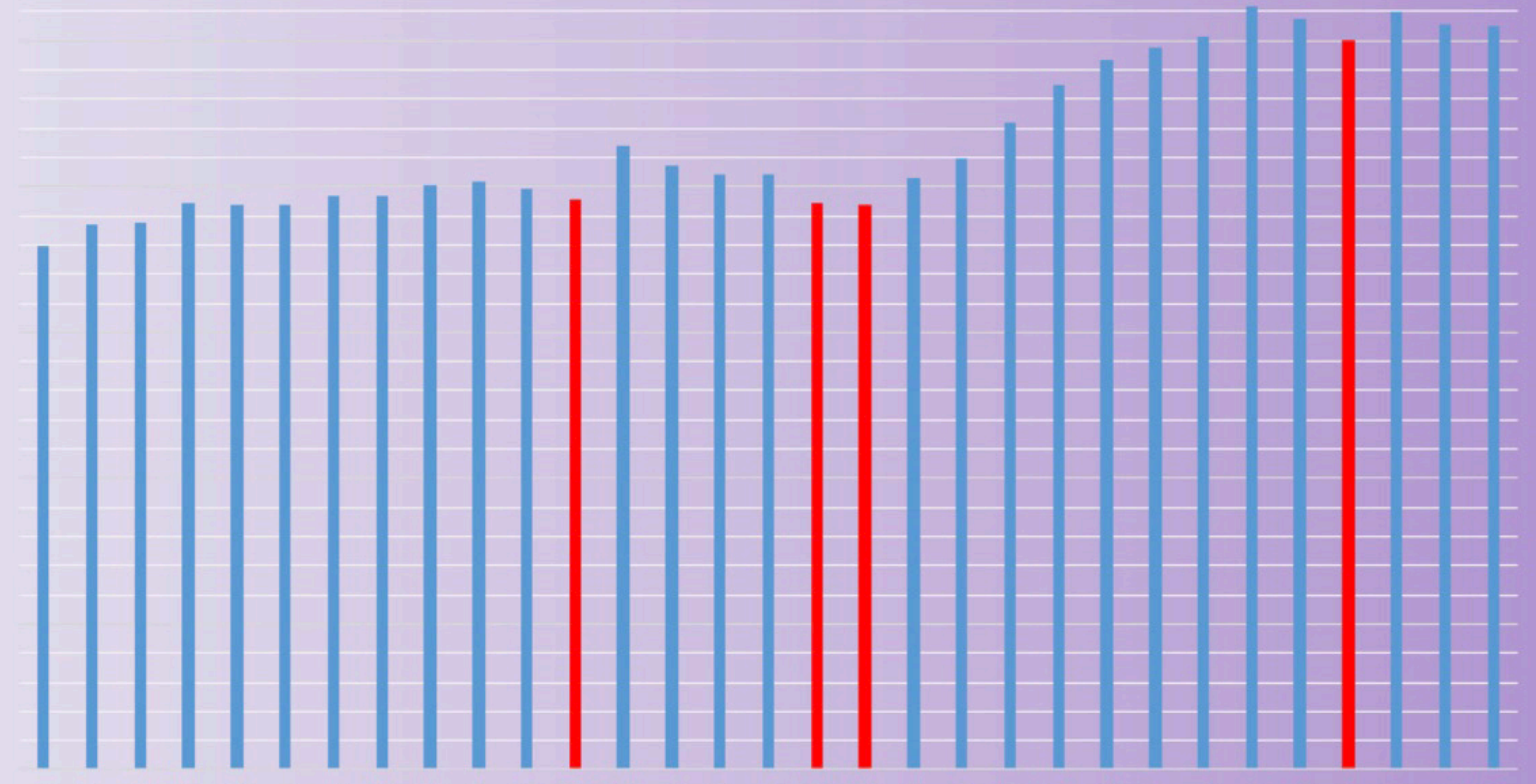

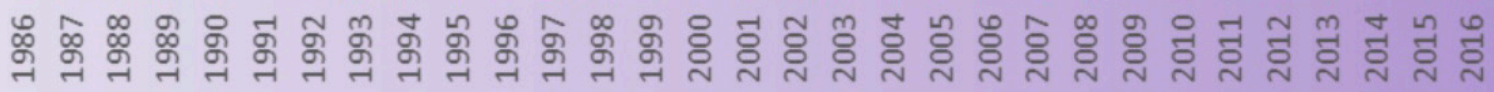


De Prácticas y discursos

Universidad Nacional del Nordeste

Centro de Estudios Sociales

Año 9, Número 14, 2020, Octubre

ISSN 2250-6942

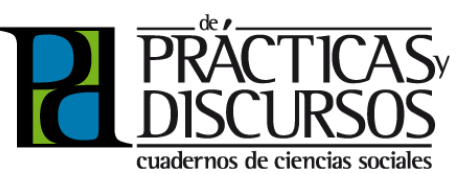

${ }^{25}$ Datos obtenidos del INE, series históricas. Tasas de empleo recuperado el 2/12/17 de: http://www.ine.gub. uy/actividad-empleo-y-desempleo.

${ }^{26}$ Datos obtenidos de INE, series históricas. Tasas de empleo recuperado en: http://www.ine.gub.uy/actividad-empleo-y-desempleo.

\footnotetext{
${ }^{27}$ Tasa de empleo femenino (INE, 2015).
}

El Gráfico 8 representa su movimiento en los últimos 30 años. En 1986, esta tasa tomaba un valor de 35,9, llegando en 2011 a la cifra más alta dentro del período representado: $52,4^{25}$. Las líneas en rojo señalan los descensos más significativos con relación a los valores de los años próximos. Los mismos se registraron en 1997 (39,1), 2002 (38,9), 2003 $(38,8)$ y $2013(50,1)$

El otro indicador utilizado con respecto al ingreso de la mujer al mercado laboral es la Tasa de actividad femenina. Su cálculo mantiene igual criterio que la Tasa de actividad general, entendida como "el porcentaje entre la población económicamente activa total (ocupados más desocupados) sobre la población total" (Neffa, Panigo, Pérez y Giner, 2005: 48). La tasa de actividad que incorpora la Población Económicamente Activa (PEA) y la Población en Edad de Trabajar (PET) adquiere valores específicos si considera en su ecuación solo a un grupo particular de población: las mujeres (en este caso). Los estudios referidos a dicho grupo específico muestran una variación significativa en las últimas cinco décadas.

El crecimiento de las tasas de participación femenina es uno de los hechos destacados desde fines de la década del 70 a la fecha, al punto de haber aumentado en más de un 50\% (téngase en cuenta que, mientras en 1969 la tasa promedio anual de actividad femenina fue del 27.4\%, en 1997 fue 46.1\%). (Ferre y Rossi, 2002: 6)

El Gráfico $9^{26}$ muestra las variaciones de la Tasa de actividad femenina dentro del periodo (1986-2016), representando su valor $(41,4)$ desde 1986 , al punto más alto alcanzado $(57)$ en 2011. Se lo presenta junto a la Tasa de empleo para comparar las variaciones de ambas tasas. La medición de esta tasa en edades centrales aporta información relevante, ya que las cifras se distancian del promedio. "Durante el periodo 1991-97 la tasa de actividad de las mujeres entre 25 y 55 años creció 5.1 puntos porcentuales pasando de 64,6\% a 69,7\%" (Ferré y Rossi, 2002: 6). En particular, en 2014, el valor general se ubicó en $56,9 \%$, mientras que en igual tramo de edades el valor ascendió a 75,6\% 27 . 
Gráfico 9. Tasas de actividad y empleo femenino - período 1986 2016 (datos INE - Localidades de más de 5.000 habitantes - elaboración propia)

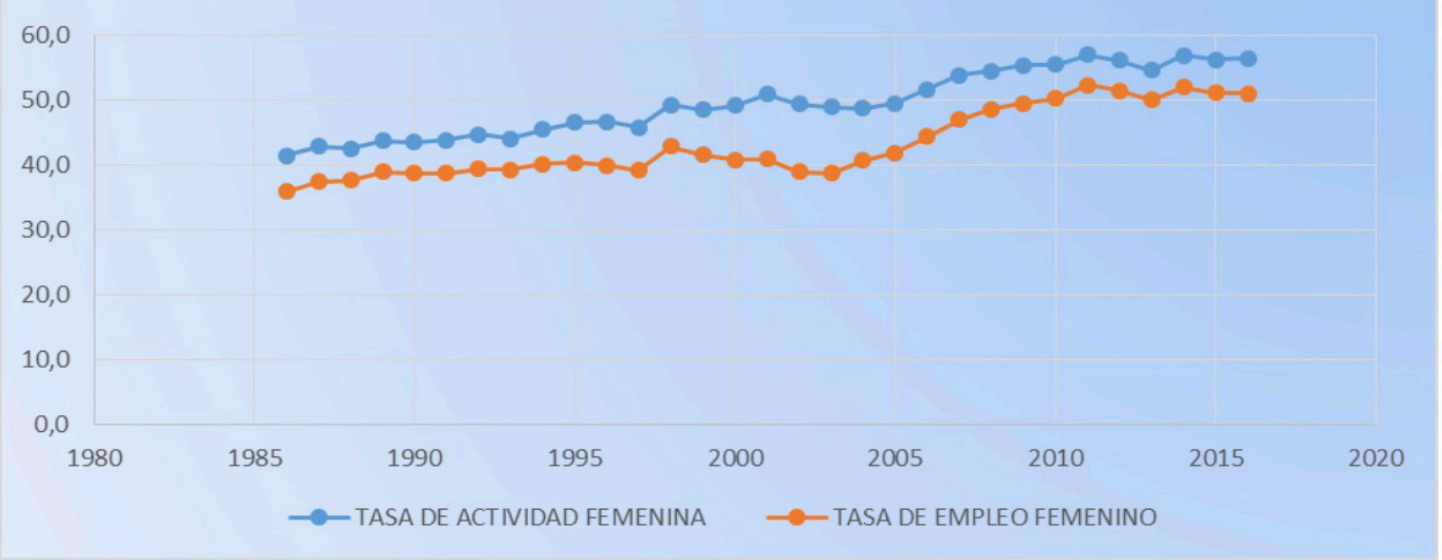

El segundo factor que se propone revisar con relación al cuidado humano refiere a la cantidad de hijos. La disminución de los nacimientos y la emigración internacional forman parte de los procesos ocurridos en Uruguay en los últimos cincuenta años, que contribuyeron a explicar el descenso del crecimiento poblacional y el consecuente envejecimiento de la estructura de edades: "El efecto de un saldo migratorio negativo durante un período prolongado, así como un nuevo 'ajuste' de la fecundidad afectaron la tasa de crecimiento poblacional y acentuaron la tendencia al envejecimiento de la población" (Pellegrino, 2003: 28).

Con relación al estudio de la disminución de los nacimientos, se toman dos indicadores: la fecundidad y la Tasa de natalidad. La fecundidad es un concepto referido a la cantidad de hijos que una mujer tiene entre los 15 y los 49 años, entendido este tramo etario como "edad reproductiva". Se mide a través de la Tasa de fecundidad general "que indica el número de hijos nacidos vivos cada 1.000 mujeres en edad reproductiva" (Pellegrino et al., 2008: 4). Para ello, se analiza la Tasa global de fecundidad (TGF) entendida como:

el número de hijos que, en promedio, tendría cada mujer de una cohorte hipotética de mujeres no expuestas al riesgo de muerte, desde el inicio hasta el fin del período fértil y que, a partir del momento en que se inicia la reproducción, están expuestas a las tasas de fecundidad por edad del momento de las poblaciones en estudio (Pellegrino et al., 2008: 5). 
De Prácticas y discursos

Universidad Nacional del Nordeste

Centro de Estudios Sociales

Año 9, Número 14, 2020, Octubre

ISSN 2250-6942

\footnotetext{
${ }^{28}$ Tasa global de fecundidad por departamento al 30 de junio de cada año, período 1996-2025.
}

La Tasa global de fecundidad mantuvo un comportamiento de descenso constante a lo largo de todo el periodo estudiado, con excepción de mediados de la década de los años 70. Este descenso llevó a alcanzar "en el año 2000 una tasa global de fecundidad (TGF) de 2,2 hijos por mujer" (Varela, 2004: 406).

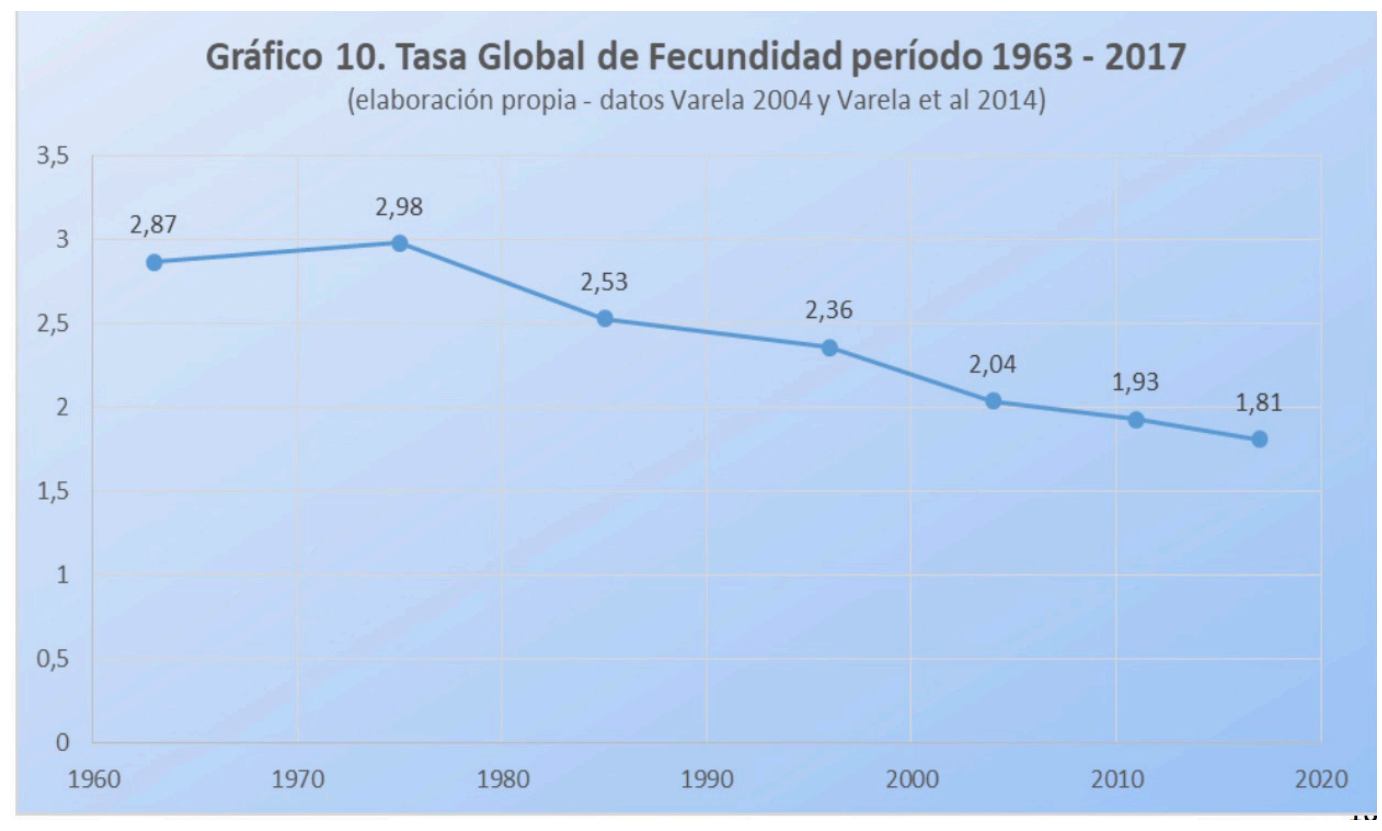

Como muestra el Gráfico 10, la tasa bajó de 2,87 (hijos nacidos por mujer) en 1963 a 1,81 en $2011^{28}$ (INE). Esta cifra la sitúa por debajo del límite de reemplazo poblacional, el cual es de 2,08 hijos por mujer (Pellegrino et al., 2008: 5). El concepto "reemplazo poblacional" hace referencia a "la capacidad de una población de sustituirse a través de la reposición numérica de las mujeres, futuras procreadoras" (Pellegrino et al., 2008: 2). La comparación de estas cifras con otros paises ubica al Uruguay en un lugar diferencial. En la región se proyecta para el período 2045-2050 una Tasa de fecundidad de 1.9 hijos por mujer (Cepal, 2009: 146). Por su parte, la Tasa de natalidad (llamada también Tasa bruta de natalidad) refiere al número de nacidos vivos por 1000 habitantes en un año específico (Haupt y Kane, 2003). En Uruguay, en 2015 se ubicó en 14,14\% (INE, 2011), estando fuertemente influida por variables como la fecundidad y la estructura de edades e incide directamente en el crecimiento de la población.

Con respecto a los cambios en la Tasa de natalidad en Uruguay, el Gráfico 11 muestra cómo en el periodo 1963-2015 desciende de 21,69 a 7,55\% en medio siglo. 


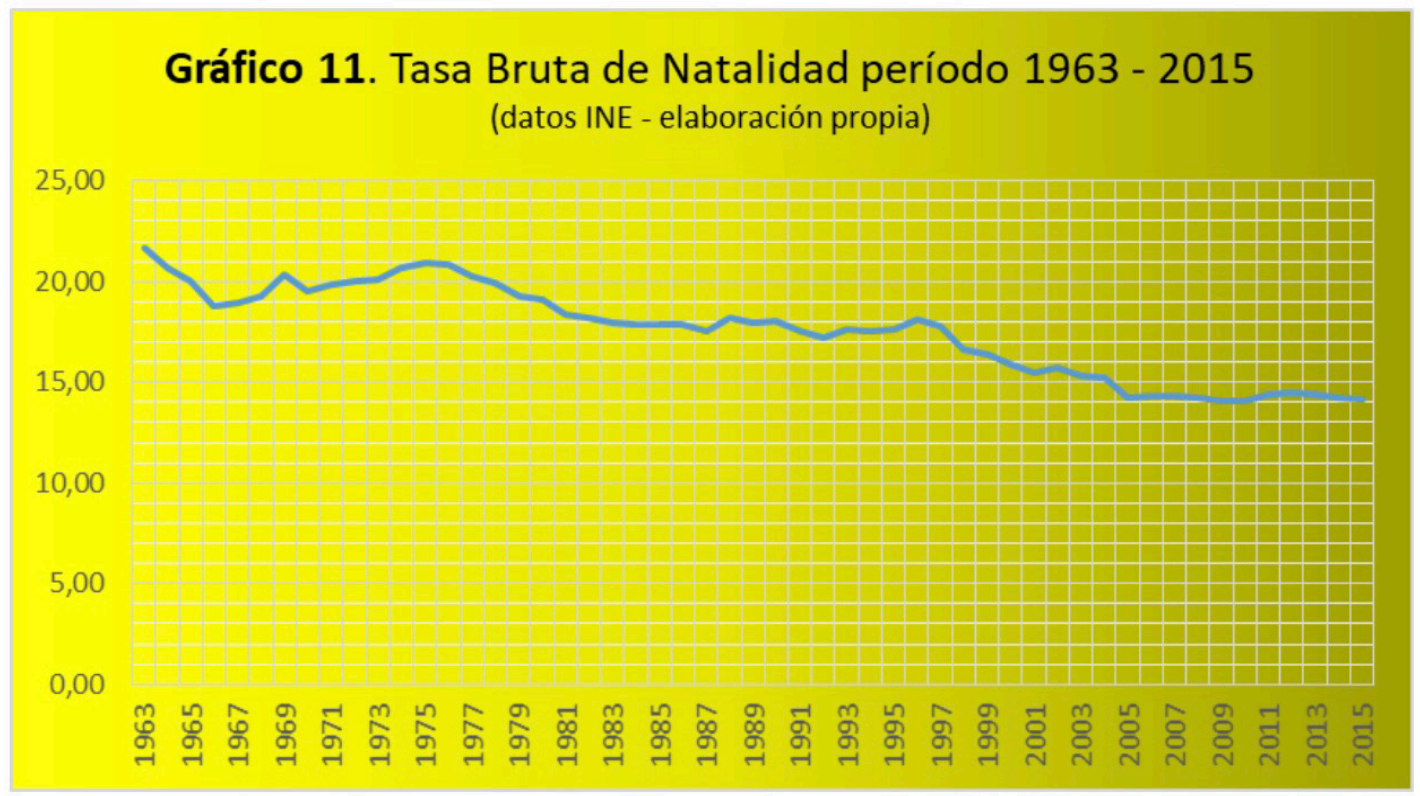

Concomitantemente a la disminución de los nacimientos, la inmigración tuvo una importancia determinante hasta la primera mitad del siglo XX en Uruguay. "El censo de 1963 registró que la población uruguaya tenía un $8 \%$ de inmigrantes y que en Montevideo alcanzaban a 13,5\% del total de la población; estos guarismos ubicaban al Uruguay dentro del conjunto de países considerados < paises de inmigración>" (Cabella y Pellegrino, 2010: 11). Por otra parte, la emigración en este periodo se dirigía a los paises limitrofes.

En cambio, la segunda mitad del siglo XX y los primeros años del siglo XXI caracterizaron a Uruguay por un saldo migratorio negativo. Se registró el fin de la corriente inmigratoria europea y el retorno a sus países de origen de una parte de la población que había llegado en décadas anteriores (Cabella y Pellegrino, 2010). Sumado a esto, el aumento de la emigración de la población uruguaya afectó el crecimiento poblacional, llegando el mismo por momentos a registrar valores negativos (Pellegrino, 2013). En la nueva etapa se modificaron también los países receptores de los emigrantes uruguayos facilitado por la nacionalidad obtenida a partir de los antepasados inmigrantes (Pellegrino, Cabella, Paredes, Pollero y Varela, 2008).

Dentro de este segundo período, los picos de emigración estuvieron particularmente vinculados a situaciones de crisis politicas (1973) y económicas (1981 y 2002). Sobre la base de datos censales se estima "que el saldo neto migratorio negativo produ- 
De Prácticas y discursos

Universidad Nacional del Nordeste

Centro de Estudios Sociales

Año 9, Número 14, 2020, Octubre

ISSN 2250-6942

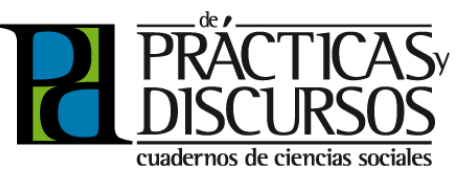

${ }^{29}$ Se considera para su medición las entradas y salidas del aeropuerto de Carrasco. cido entre 1963 y 1985 alcanzó un volumen de 310.000 personas, equivalente al 11\% del total de la población media del país en el período" (Pellegrino, 2003: 28). Estos porcentajes ubicaron a nuestro país (junto con Paraguay) "con la tasa de emigración más alta de América del Sur" (Pellegrino, 2003: 28). En el siguiente periodo intercensal (1985-1996), el saldo continuó siendo negativo, estimado el mismo en 60000 personas, registrándose un saldo positivo ${ }^{29}$ solo en 1996, 1998 y 1999 (Pellegrino, 2003).

Producto de la crisis económica de comienzos del siglo XXI, el saldo migratorio negativo para el periodo 1996-2006 se estima en "126.000 personas, alrededor del 3,7\% de la población media total del pais" (Cabella y Pellegrino, 2010: 11). Este porcentaje se incrementa si se enfoca la atención en el comienzo del nuevo siglo.

A partir del 2000 el saldo negativo aumenta significativamente, llegando a más de 18.000 en el año 2000, más de 20.000 en 2001 y 28.000 en 2002. Una idea de la magnitud de estos valores del saldo de movimientos de uruguayos por el aeropuerto internacional, es que los mismos son próximos al total del crecimiento natural de la población en los dos primeros años señalados, y lo superan en el 2002 (Pellegrino, 2003: 30).

Otros dos aspectos participan en la temática de la pérdida de capacidad cuidadora de la familia y la comunidad. El primero es el perfil de los emigrantes de comienzos del siglo XXI. Se trata de una población económicamente activa, en edades reproductivas y con un nivel educativo por encima del promedio del país (Pellegrino, 2003). Las franjas etarias que caracterizan a esta población se evidencian en la pirámide poblacional a través del "afinamiento de los grupos de edad entre los 20 y los 29 años, y en menor medida entre los 30 y los 44" (Cabella y Pellegrino, 2010: 14). Como resultado, la población que pierde el pais impacta negativamente en su "potencial reproductivo", reforzando el cambio en la estructura de edades y el consecuente envejecimiento poblacional (Cabella y Pellegrino, 2010: 14).

Un último aspecto a mencionar es lo que Pellegrino denomina "cultura emigratoria", la cual refuerza la salida de la población joven. La misma se configura a partir del "estancamiento económico prolongado" y de las constantes corrientes emigratorias de las últimas décadas (Pellegrino, 2003: 29). La suma de estos factores ubicaron hasta entrado el siglo XXI a la emigración en Uruguay como un "fenómeno estructural" (Pellegrino et al., 2008: 15). 
En próximas décadas se podrá analizar la incidencia en los sistemas de cuidados de la corriente inmigratoria que ha llegado a Uruguay en los últimos años, considerando tanto a la población uruguaya como a la población inmigrante, incluyendo a los miembros de sus familias que han permanecido en su país de origen.

\section{REFLEXIONES FINALES}

Las variables demográficas presentadas sobre el caso uruguayo dan cuenta de las transformaciones registradas en las últimas décadas en el país. En estas se verifican movimientos que condicen con procesos registrados en otros paises y, al mismo tiempo, se identifican singularidades nacionales. Como dice Van de Kaa (2002: 30), es una información valiosa en tanto da cuenta que "en cualquier momento cada país o región tiene su propio patrimonio demográfico y dotación cultural".

El estudio de la información puede enfocarse desde distintos ángulos. Con relación a la población adulta mayor que requiere cuidado, cabe destacar el alto índice de envejecimiento de la sociedad uruguaya, el "sobreenvejecimiento" y la feminización de la vejez. Al mismo tiempo, el aumento de la "discapacidad", a medida que se envejece, deriva en que la cuarta parte de la población del país presenta a partir de los 75 años necesidades de apoyo para las actividades de la vida diaria. Estos datos toman un nuevo significado cuando se enmarcan en el hecho de que más de la mitad (55,32\%) de la población Adulta Mayor en Uruguay vive en hogares unipersonales o de pareja sin hijos, aumentando esta proporción en las mujeres a medida que avanza la edad (59,85\%).

Otro ángulo que complementa al anterior está dado por las transformaciones en la población a la que se le asigna el rol de cuidado. Por un lado, el cambio de tendencia en los tipos de hogares no colabora con posibles estrategias de apoyos familiares. Por otro lado, el saldo migratorio negativo que caracterizó la segunda mitad del siglo XX y los comienzos del siglo XXI, el perfil de los emigrantes de las últimas décadas compuesto por población económicamente activa y en edades reproductivas (20 y 44 años), la disminución de la Tasa de natalidad (un hijo menos por mujer entre 1963 y 2011), han llevado a que quienes hoy tienen más de 65 años cuenten en su núcleo familiar con menos población cuidadora que hace medio siglo. Esta situación deriva además en que la población adulta mayor tiende a convertirse a 
De Prácticas y discursos

Universidad Nacional del Nordeste

Centro de Estudios Sociales

Año 9, Número 14, 2020, Octubre

ISSN 2250-6942

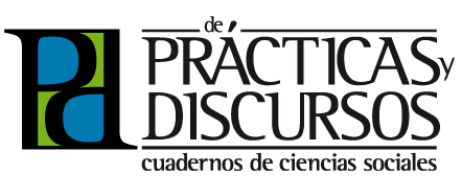

su vez en cuidadora de distintos grupos etarios en general y de la población sobreenvejecida en particular. Es un dato significativo al respecto que, en Uruguay, la relación de los adultos mayores con la población en edad de trabajar es la más alta de Hispanoamérica (Thevenet, 2013).

Un tercer ángulo de lectura lo aporta la modificación del patrón de proletarización que implicó el pasaje de aportante único a aportante múltiple, impactando en la reproducción y la organización de la vida toda (Danani, 2009). De este modo, los nuevos requerimientos del sistema implicaron no solo el ingreso de la mujer en el mercado laborar, sino su participación en una doble jornada de trabajo, desde un doble rol (productivo y reproductivo). El nuevo rol productivo de la mujer se solapó con las responsabilidades al cuidado históricamente asignadas, identificándose por lo menos tres aspectos vinculados que importan mencionar. El primero es el cambio cultural relacionado con el ingreso de la mujer al mercado laboral y su proyecto de desarrollo personal que entró en contradicción con su rol cuidador y doméstico. La información estadística señala la vinculación entre aumento de la participación de la mujer en el mercado laboral y la disminución de los nacimientos (Cabella y Pellegrino, 2010).

Un segundo aspecto es que los espacios públicos y privados se presentan desvinculados entre sí, cuando "lejos de ser entidades independientes, el ámbito llamado privado o de la familia y el ámbito llamado público se encuentran atravesados y vinculados por relaciones profundas y dialécticas" (Ezquerra, 2011: 184). En esta fragmentación se encubre, a través de su naturalización y falta de remuneración, lo esencial de la tarea de reproducción y el cuidado de la vida para el mantenimiento del sistema económico en general (Ezquerra, 2011).

El tercer aspecto es la tendencia en Uruguay de continuar depositando la responsabilidad en las situaciones particulares (familia-comunidad) que requieran cuidados, sin considerar los cambios registrados en la estructura sociofamiliar. Es una idea que se enmarca en procesos denominados de "familiarización" y "comunitarización", entendidos como aquellos que con relación al cuidado "representan una concepción que define y asigna la responsabilidad del mismo al par familia/comunidad basado en el mismo principio: el de la naturalización y la 'primarización' concebidas como pre política" (Danani, 2009: 39). Desde esta perspectiva, "los 'problemas sociales' terminan 


\footnotetext{
${ }^{30}$ Los actores intervinientes en el concepto de "organización social del cuidado" se corresponden con los considerados en el "diamante del cuidado" (Razavi, 2007): Estado, comunidad, mercado, familia.
}

siendo identificados con 'fallas familiares' (Cochrane, 1997) o comunitarias" (Danani, 2009: 44).

La lectura establecida desde una lógica individual, privada y fragmentada obtura la visualización colectiva del problema, debilitando a los movimientos sociales tendientes a colocar el tema en la agenda pública y establecer presión para la implementación de respuestas a través de políticas sociales. El problema del cuidado no es un problema particular de quienes lo requieren y de la población que lo presta, es un tema que atañe a toda la sociedad, a las generaciones actuales y futuras, en tanto se comprende como un derecho universal "independientemente del estado de necesidad que eventualmente esté transitando la persona" (Rodríguez y Marzonetto, 2016: 107).

La denominada economía de cuidado aporta a esta perspectiva. "En un sentido amplio, el contenido del concepto refiere a todas las actividades y prácticas necesarias para la supervivencia cotidiana de las personas en la sociedad en que viven" (Rodríguez, 2015: 36). Para llevar adelante estas prácticas, se requiere la participación de múltiples actores que en forma interrelacionada y dinámica se involucren aportando distintas estrategias y recursos. En esta organización social del cuidado intervienen ${ }^{30}$ "las familias, el Estado, el mercado y las organizaciones comunitarias" (Rodríguez y Marzonetto, 2016: 105).

El Estado uruguayo, hasta hace escasos años (2015), centró su participación en un rol regulador de la actividad privada, desvinculándose significativamente de la prestación de servicios. Aun en este escenario, el rol de control público sobre la actividad privada ha sido deficitario. Se suma a lo anterior la casi inexistente información producida y publicada sobre la temática, lo cual no solo ha ocultado su real dimensión, sino que también ha obstaculizado durante décadas su politización, evitando el debate público.

La reciente ley de cuidados (Ley 19353 del Sistema Nacional Integrado de Cuidados de 2015), si bien muestra un cambio de paradigma necesario, no resulta suficiente para tener un impacto considerable sobre la situación planteada. La escasez de recursos asignados para su implementación con relación a la dimensión del problema, y su variación en determinadas coyunturas políticas, profundiza las dificultades para hacer efectivo el derecho al cuidado de la población uruguaya.

De este modo, el mercado en Uruguay ha resultado ser hasta el momento el principal prestador de servicios de cuidado para la 
De Prácticas y discursos

Universidad Nacional del Nordeste

Centro de Estudios Sociales

Año 9, Número 14, 2020, Octubre

ISSN 2250-6942

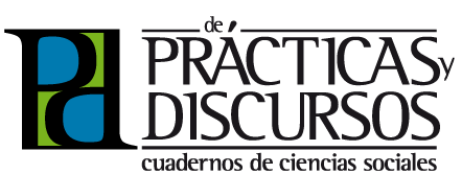

familia que los requiere. Para dimensionar el pago de los servicios de cuidado por parte de la población, se debe de atender que la salida del mercado laboral en la vejez repercute en la estructura económica de su sobrevivencia, ya que la distribución primaria percibida a través del empleo se reduce en un 50\% frente a la pasividad (jubilación-pensión), quedando limitada a percibir una distribución secundaria del ingreso "cuyo rasgo fundamental es que sólo existe por mediación estatal" (Danani, 2009: 32). De esta forma, la "pasividad" implica por tanto no solo la pérdida de capacidad de presión para exigir mejores condiciones de consumo, sino que restringe, en un porcentaje significativo de población, la posibilidad de compra de satisfactores de necesidades básicas, entre otras, las formas de cuidado que el mercado ofrece.

La concentración del cuidado en el ámbito privado, y la escasa regulación estatal, ha llevado además al "cuidado como experiencia socioeconómicamente estratificada", debido a que a través del mercado, "los hogares pertenecientes a diferentes estratos económicos cuentan con distintos grados de libertad para decidir la mejor manera de organizar el cuidado de las personas" (Rodríguez, 2015: 42).

En suma, el cuidado de la vejez que requiere apoyos para desempeñar actividades en su vida diaria se configura como problema en tanto los recursos necesarios para implementar la solución no se corresponden con los existentes en el ámbito estatal como familiar y comunitario. Más allá de la importancia que la información sociodemográfica reviste en sí misma, esta interesa en la medida en que aporta complejidad a la lectura de la temática. Dicha complejidad resulta necesaria para romper con la fragmentación del discurso que ubica a cada familia o grupo comunitario como responsable del problema particular, desdibujando la corresponsabilidad inherente a los distintos actores en tanto el cuidado se entienda como derecho de la sociedad en su conjunto.

\section{BIBLIOGRAFIA}

AGUIRRE, R. Y SCURO, L. (2008). Uso del tiempo y trabajo no remunerado en el Uruguay. Módulo de la Encuesta Continua de Hogares. Montevideo: Facultad de Ciencias Sociales, Departamento de Sociología, Instituto Nacional de Estadistica, División Estadísticas Sociodemográficas, UdelaR, Unifem. Versión electrónica. 
BATTHYÁNY, K. ET AL. (2014). Fascículo 5. Desigualdades de género en Uruguay. En Calvo, J.C. (coord.) Atlas sociodemográfico y de la desigualdad en Uruguay. Programa de Población. Montevideo: Trilce.

BRUNET, N. Y MÁRQUEZ, C. (2016). Fascículo 7. Envejecimiento y personas mayores en Uruguay. En Calvo, J.C. (coord.) Atlas sociodemográfico y de la desigualdad del Uruguay. Montevideo: Trilce.

CABELLA, W. Y PELLEGRINO, A. (2005). Una estimación de la emigración internacional uruguaya entre 1963 y 2004. Documento de Trabajo/FCS-UM; 70.

(2010). "El envejecimiento de la población uruguaya y la transición estructural de las edades". Trabajo presentado en las IX Jornadas de Investigación de la Facultad de Ciencias Sociales, UdelaR, (on line). Montevideo, 13-15 de setiembre de 2010). Recuperado dewww.fcs.edu.uy/archivos/Mesa_30_ cabella_pellegrino.pdf)

CABELLA, W.; FERNÁNDEZ, M. Y PRIETO, V. (2015). Fascículo 6. Las transformaciones de los hogares uruguayos vistas a través de los censos de 1999 y 2011. En Calvo, J.C. (coord.) Atlas Socioeconómico y de la desigualdad en Uruguay. Montevideo: Trilce. ISBN: 978-9974-32-645-3.

DANANI, C. (2009). La gestión de la política social: un intento de aportar a su problematización. En Chiara, M. y Di Virgilio, M. (comp.) Gestión de la política social. Conceptos y herramientas. Buenos Aires: Prometeo, UNGS.

EZOUERRA, S. (2011). Crisis de los cuidados y crisis sistémica: la reproducción como pilar de la economía llamada real. Investigaciones feministas, (0)2, 175-194.

FERRÉ, Z. Y ROSSI, M. (2002). Segregación ocupacional de la mujer en el mercado de trabajo del Uruguay (1986-1997). Documentos de trabajo No. 05/02. Departamento de Economía, Facultad de Ciencias Sociales, UdelaR. 
FRENK, J. ET AL. (1991). La transición epidemiológica en América Latina. Bulletin of the Pan American Health Organization, III, 485-496.

HAUPT, A. Y KANE, T.T. (2003). Guia Rápida de Población (4a ed.) Washington DC: Population Reference Bureau.

INSTITUTO NACIONAL DE ESTADÍSTICA (2011). Censo 2011. Recuperado de http://www.ine.gub.uy/censos2011/resultadosfinales

INSTITUTO NACIONAL DE ESTADíSTICA (1996). Manual del Empadronador. VII Censo General de Población, III de Hogares y $\checkmark$ de Viviendas. Uruguay: Centro Latinoamericano y Caribeño de Demografia (Celade). Recuperado de http://www.ine.gub.uy/c/ document_library/get_file?uuid=09295a3f-7499-4b39-a3aa2b2bded9d1d7\&tgroupld $=10181$

INSTITUTO NACIONAL DE LAS PERSONAS MAYORES (2016). Resultados del relevamiento de establecimientos de larga estadía 2015. Recuperado de www.mides.gub.uy/innovaportal/file/63440/1/censo.pdf

MINISTERIO DE SALUD PÚBLICA (2005/2010). Programa Nacional Del Adulto Mayor. Dirección General de la Salud. División Salud de la Población (on line). Recuperado de: www2.msp. gub.uy/andocasociado.aspx?5682,21570

NEFFA, J.C.; PANIGO, D.T.; PÉREZ, P.E. Y GINER, V. (2005). Actividad, empleo y desempleo: conceptos y definiciones. Ceil-Piette Conicet.

PAREDES, M. (2008). Demografía y seguridad social en Uruguay: balance y perspectivas. Diálogo nacional sobre seguridad social. Recuperado de: www.bps.gub.uy/Escritos\%5CAportes $\% 20$ al\%20debate

PAREDES, M.; CIARNIELLO, M. Y BRUNET, N. (2010). Indicadores sociodemográficos de envejecimiento y vejez en Uruguay: una perspectiva comparada en el contexto latinoamericano. Espacio Interdisciplinario-Universidad de la República, Núcleo In- 
terdisciplinario de Estudios sobre Vejez y Envejecimiento, UNFPA. Universidad de la República. Uruguay: Lucida ediciones.

PELLEGRINO, A. (2003). Caracterización Demográfica del Uruguay. UNFPA-Programa de Población, Facultad de Ciencias Sociales. Montevideo: UDELAR (on line). Recuperado de: http://www3.anep. edu.uy/historia/clases/clase20/cuadros/15_Pellegrino-Demo.pdf

(2013). Uruguay: cien años de transición demográfica. Migración y Desarrollo, 11 (20), 186-207. Recuperado de: www. redalyc.org/html/660/66028343007/ (29 de noviembre de 2017).

PELLEGRINO, A.; CABELLA, W.; PAREDES, M.; POLLERO, R. Y VARELA, C. (2008). De una transición a otra: la dinámica demográfica del Uruguay en el siglo XX. En Nahum, B. (ed.) Uruguay en el siglo XX: la sociedad. Montevideo: Ediciones de Banda Oriental.

POSSAS, C. DE A. (1993). "La transición demográfica en América Latina" en IV Conferencia Latinoamericana de Población. Vol. II. INEGI-IISUNA.

PUGLIESE, L. (2007). Análisis Comparado de una Selección de Programas de Protección a los Adultos Mayores en Argentina, Brasil, Chile y Uruguay. Segunda Parte: Programas Sociales. Asesoria General en Seguridad Social. Comentarios de Seguridad Social, 16. Recuperado de: https://www.bps.gub.uy/.../programasde-proteccion-a-adultos-mayores-en-argentina-...

RAZAVI S. (2007). The political and social economy of care in a development context conceptual issues. Research Questions and Policy Options. UNRISD. Recuperado de: http://www.unrisd. org/80256B3C005BCCF9/(httpAuxPages)/2DBE6A93350A7783C 12573240036D5 A0/\$file/Razavi-paper.pdf

ROBLES GONZÁLEZ, E.; BERNABEU MESTRE, J. Y BENAVIDEZ, F.G. (1996). La transición sanitaria: una revisión conceptual. Boletín de la Asociación de Demografía Histórica, XVI, I, 117-144.

RODRÍGUEZ ENRÍQUEZ, C.M. (2015). Economía feminista y economía del cuidado: Aportes conceptuales para el estudio de la desigualdad. Nueva Sociedad, 256, pp. 30-44. 
RODRÍGUEZ ENRIQUEZ, C.M. Y MARZONETTO, G.L. (2016). Organización social del cuidado y desigualdad: el déficit de politicas públicas de cuidado en Argentina.

SAAD, P.M.; MILLER, T.; HOLZ, M. Y MARTÍNEZ, C. (2012). Juventud y bono demográfico en Iberoamérica. Cepal/OIJ. Recuperado de: https://www.cepal.org/cgi-bin/getProd.asp?xml=/celade/noticias/...

THEVENET, N. (2013). Cuidados en personas Adultas Mayores. Análisis descriptivo de los datos del censo 2011. Montevideo: Departamento de Investigación y Propuestas. Área de Protección Social. Asesoria Marco en Políticas Sociales Ministerio de Desarrollo Social.

URUGUAY. PODER EJECUTIVO (2015). Ley 19353 del Sistema Nacional Integrado de Cuidados. Recuperado de: https:// www.impo.com.uy/bases/leyes/19353-2015

VAN DE KAA, D.J. (2002). The idea of a second demographic transition in industrialized countries. Birth, 35, 45.

VARELA, C. (2004). El reemplazo de la población en Uruguay, un fenómeno ausente en la agenda estatal. En La fecundidad en América Latina, ¿transición o revolución? (pp. 399-420). Santiago de Chile: Cepal.

VERA, P.S. (1996). Tercera y cuarta edad en España desde la perspectiva de los hogares. Reis, 57-79. 